\title{
Anjos e demônios modernos
}

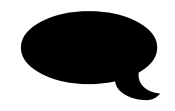

Marcelo Bolshaw Gomes ${ }^{1}$

Universidade Federal do Rio Grande do Norte

Resumo: Estuda três conhecidos super-heróis de histórias em quadrinhos: o Surfista Prateado, o Demolidor (ambos da Marvel Comics) e o Batman (da DC Comics). O objetivo é mostrar a universalidade de algumas das características desses super-heróis com os dramas humanos do cotidiano e com as narrativas míticas. Utiliza a análise narrativa dos personagens para descreve-los e compará-los com entes das mitologias tradicionais. Conclui que os heróis 'Surfista Prateado' e 'Demolidor' (Daredevil) correspondem a estruturas míticas arcaicas de diferentes formas de representação da própria identidade. Nessa ótica, há super-heróis (Demolidor, Homem-Aranha e Batman) que vivem sem esperanças, presos no mundo imanente, e representam a relação Ego-Id; e outros superheróis (Surfista Prateado, Thor, Mulher Maravilha e Super-Homem) que caíram' de um universo transcendente e correspondem a relação Ego-Self.

Palavras-chave: Comunicação midiática1; história em quadrinhos; teoria narrativa.

Abstract: It studies three well-known comic book superheroes: Silver Surfer, Daredevil (both from Marvel Comics) and Batman (from DC Comics). The goal is to show the universality of some of the characteristics of these superheroes with the daily human dramas and the mythical narratives. It uses the narrative analysis of the characters to describe them and compare them with entities of traditional mythologies. It is concluded that the heroes 'Silver Surfer' and 'Daredevil' correspond to archaic mythic structures of different forms of representation of their own identity. In this view, there are superheroes (Daredevil, Spider-Man and Batman) who live hopelessly trapped in the immanent world and represent the Ego-Id relationship; and other superheroes (Silver Surfer, Thor, Wonder Woman and Superman) who have 'fallen' from a transcendent universe and correspond to the Ego-Self relationship.

Keywordsः Media communication1; Comics; Narrative Theory. 


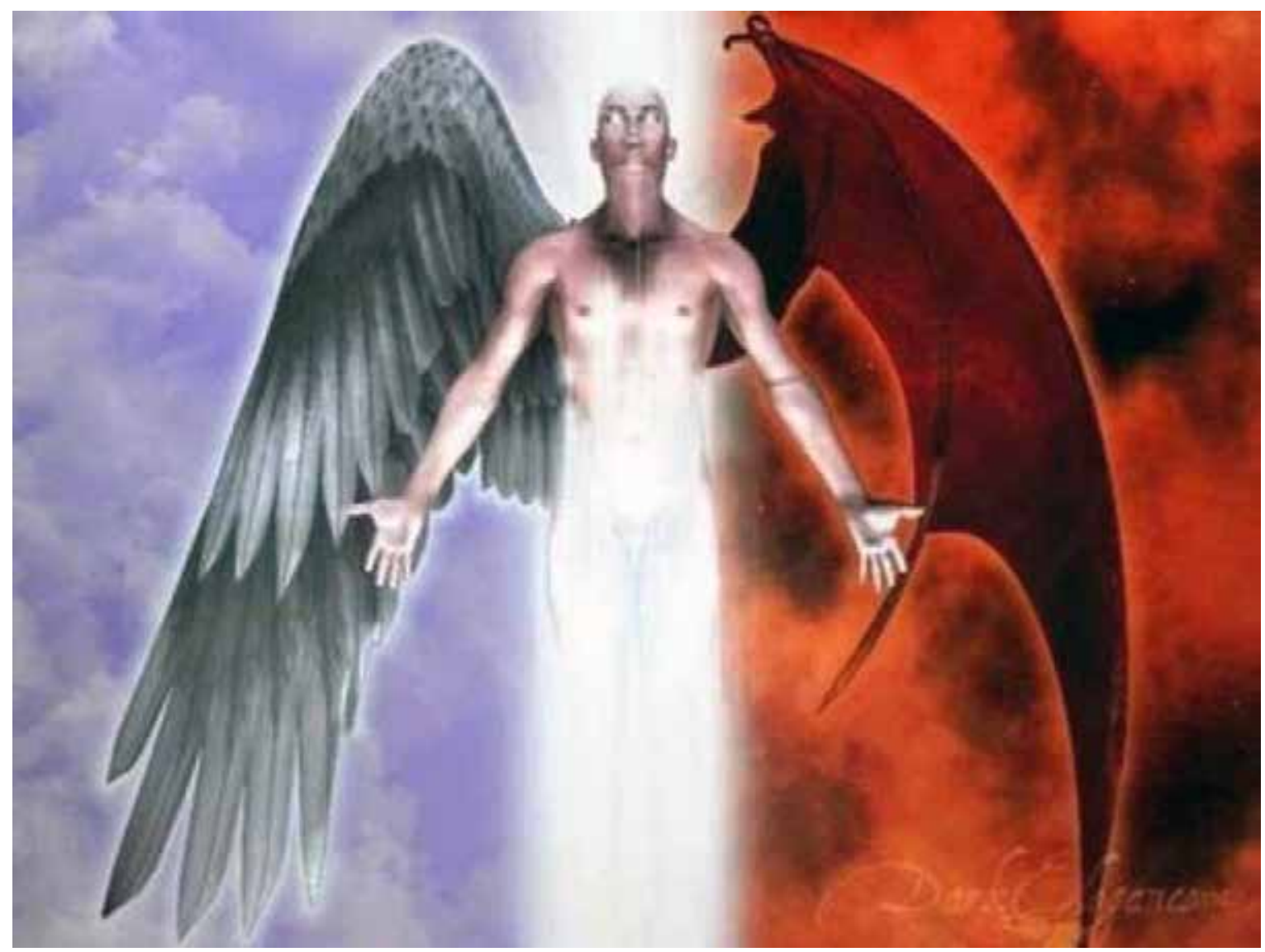

Figura 1 - Anjo / Demônio, de Caio Lima Borges Fonte: https://pt.quizur.com/quiz/ao-ganhar-poderes-voce-seria-um-anjo-ou-um-demonio-fEs

\section{Introdução}

Velhos feitiços, novos encantos!

Vestimos conteúdos simbólicos antigos com novas formas culturais: os antigos deuses do ferro se tornaram ciber vilóes, impiedosos e cheios de armas; as arcaicas deusas lunares das águas são agora representadas como entidades femininas encantadoras, que nos hipnotizam, não mais para as servir sexualmente, mas sim para nos fazer comprar e consumir bobagens. As novas formas modernas de representação guardam semelhanças e diferenças com as antigas formas tradicionais.

Este texto estuda três conhecidos super-heróis de histórias em quadrinhos: o Surfista Prateado, o Demolidor (Daredevil) e o Batman. Utiliza-se da análise narrativa dos personagens para descreve-los e comparálos com entes das mitologias tradicionais. O objetivo é demonstrar a universalidade de algumas das características dos super-heróis com os dramas humanos do cotidiano e as antigas narrativas míticas.

Ao final, destaca-se dois tipos de heroísmo distintos: um voltado para o mundo cotidiano e outro representando um protagonista universal e transcendente.

\section{1 - Definições}

O primeiro passo da análise narrativa de um determinado personagem é compreender sua função dramática na história. Não apenas se ele é protagonista, antagonista ou coadjuvante; mas também o gênero da narrativa, se é heroica, romântica, religiosa, ou de outro tipo. Nem todo protagonismo é heroico.

Após investigar durante 20 anos diferentes culturas ameríndias, realizando uma ampla a análise estrutural de 813 mitos nativos das duas Américas com algumas variantes; Lévi-Strauss publicou o maior e mais completo estudo sobre o mito do 
herói $(2004 ; 2005 ; 2006 ; 2011)$. O mito de referência é o 'desaninhador de pássaros', que serve como fio condutor de todas as análises que se seguem. A narrativa foi colhida pelo próprio Lévi- Strauss quando esteve no Brasil, estudando os índios Bororo do Mato Grosso e conta a história de um incesto cometido por um índio com sua mãe.

Ao descobrir a transgressão, o pai expulsa o filho. O herói vai para dimensões desconhecidas e rouba o fogo de seres mágicos. Em algumas dessas lendas, o fogo é dado em troca de uma aliança e de um casamento do herói nativo com a filha de seres encantados. Então, dono de grande poder, o herói retorna à sua terra e mata o pai, a mãe e todos que o humilharam no passado. $\mathrm{O}$ mito assim tanto prescreve o tabu como sua transgressão heroica e destrutiva. Os transgressores dos limites entre natureza e cultura estão destinados a se tornarem senhores do fogo e da guerra.
A estrutura do mito do desaninhador de pássaros compreende e explica, com suas variações, todas as narrativas em quatro etapas: a transgressão do tabu, o castigo, a conquista do fogo e a vingança da exclusão através da destruição generalizada. O fogo, nessa perspectiva, representa a tecnologia que transforma a Natureza (o cru) em Cultura (o cozido) (LÉVI-STRAUSS, 2004). ${ }^{2}$

Joseph Campbell (1990, 1995), comparando diferentes mitologias, elaborou um modelo chamado de Jornada do Herói, em que o herói abandona a vida ordinária, mergulha no desconhecido e retorna à dimensão cotidiana, composto de 3 fases e 17 momentos.

Vogler (1997) faz uma adaptação dessa estrutura, mantendo as três fases narrativas e reduzindo as 17 etapas para apenas 12 . Hoje esse modelo narrativo é referência para vários filmes, romances, histórias em quadrinhos e narrativas heroicas.

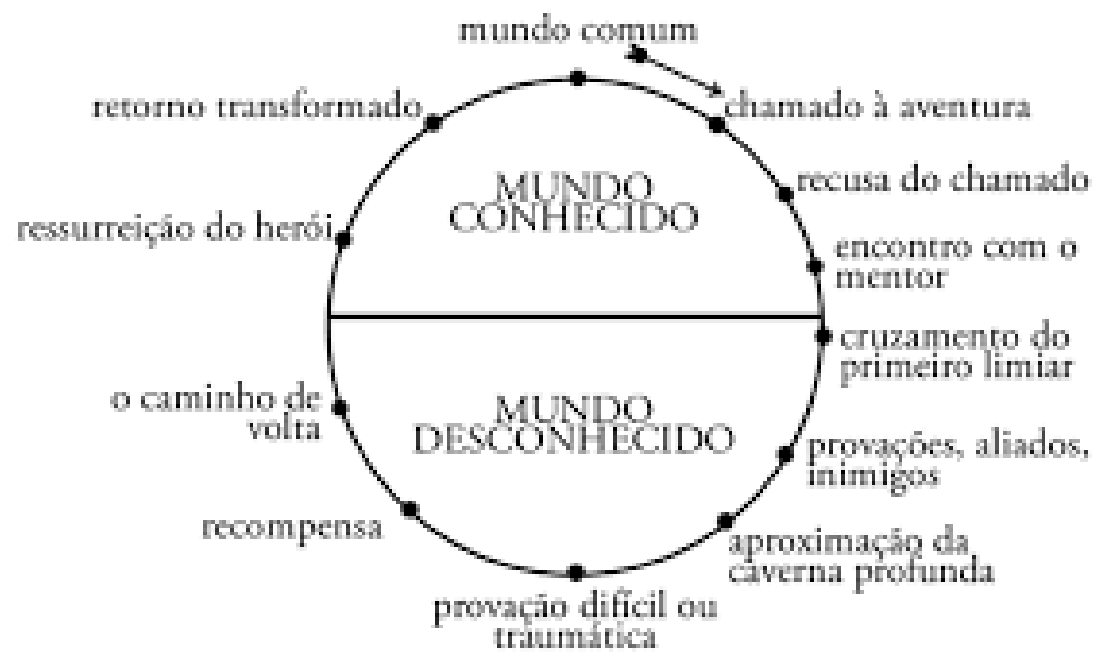

Figura 2 - A jornada do herói

Fonte: http://investidordoabc.blogspot.com/2016/10/a-jornada-do-heroi-investidor.html

Campbell defende a ideia de universalidade psicológica das narrativas (o 'Monomito'), ou seja, de que todas as histórias são na verdade a repetição de uma única estrutura narrativa. Para Campbell (1990, p. 138), "a façanha convencional do herói começa com alguém a quem foi usurpada alguma coisa". Esse ato de heroísmo, para Campbell (1990, p.141), é "o objetivo moral
2. Enquanto alguns suspeitam que o fogo, a aliança e o casamento representam a entrada do homem branco na vida indígena ou a sua previsão mítica; outros consideram que os 'homens do céu' são seres alienígenas. O fato que a descoberta do fogo desencadeou um desequilíbrio no universo humano. Os homens praticamente não caçavam nem comiam carne antes do advento do fogo controlado e até hoje não têm a anatomia e fisiologia adequadas para serem carnívoros. $\mathrm{O}$ advento do fogo nos transformou, não apenas em animais carnívoros, mas, sobretudo, em uma nova espécie predadora desequilibrando a cadeia alimentar e o meio ambiente. é o de salvar um povo, ou uma pessoa, ou defender uma ideia. O herói se sacrifica por algo". Todos os heróis precisam passar por um ciclo de "morte" e renascimento por meio do sacrifício, físico ou espiritual, a fim de alcançar um objetivo. Os heróis em suas origens "morrem" como seres comuns em determinada passagem de sua história para retornar como super-humanos. 
Segundo a presente perspectiva, um herói é um protagonista que faz coisas erradas pelos motivos certos'. Essa definição de comportamento abrange outras definições como a do mito do herói-transgressor, violento e inovador de Lévi-Strauss ou a do mito do herói espiritual da ressurreição de Campbell. Ela implica também em personagens-coadjuvantes que 'façam a coisa certa (aparentemente) pelos motivos certos' (a autoridade moral, os outros personagens, a sociedade do herói); e em personagensantagonistas (os vilões) que 'façam as coisas erradas pelos motivos errados'.

E este é um modelo, baseado em regras e em sua interpretação, simples e mais abrangente que os modelos de Lévi-Strauss e Campbell.

Outra característica marcante em boa parte das histórias heroicas são narrativas de conversão, em que vilóes que passam a tentar 'fazer o bem'. Geralmente esse comportamento caracteriza os falsos heróis', aqueles que "fazem o certo pelos motivos errados" - ou seja: o contrário simétrico ao verdadeiro herói que faz coisas erradas pelos motivos certos. Nas histórias atuais há viradas e transformações, todos heróis são falsos, ou melhor: todos somos personagens contraditórios e complexos. O'motivo certo' é algo ainda que procuramos entender.

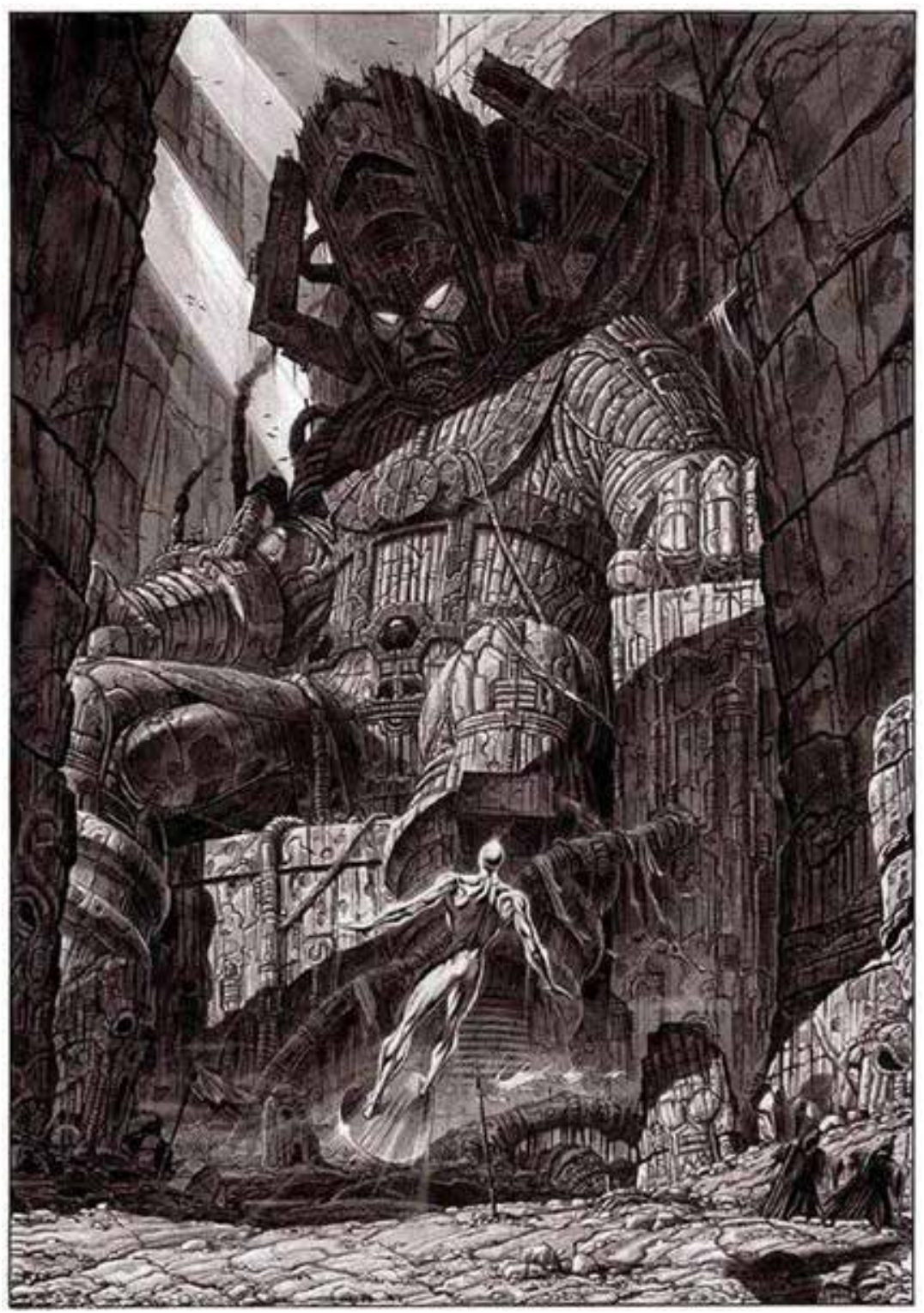

Figura 3 - Galactus e o Surfista Fonte: http://www.giantsizemarvel.com/2014/08/silver-surfer-and-galactus-by-giorgio.html 


\section{2 - Na onda do Surfista Prateado}

O Surfista Prateado é uma criação de Stan Lee e Jack Kirby. Surgiu pela primeira vez no arco de histórias em quadrinhos do Quarteto Fantástico conhecido como 'A Trilogia de Galactus' (Fantastic Four n. 48, de 1966). Em pouco tempo, o personagem tornou-se um dos heróis mais importantes do Universo Marvel, sendo repaginado do ponto de vista editorial em diferentes momentos por vários artistas. A Marvel lançou a revista do herói em 1968, com arte de John Buscema (também desenhista do bárbaro Conan). ${ }^{3}$

Em 1971, o Surfista Prateado participa do grupo de super-heróis Os Defensores,- ao lado de Namor, Hulke Doutor Estranho. Há também participação do surfista em outras histórias, como com o Homem-Aranha. Em 1989, surge a minissérie Parábola, texto de Stan Lee e arte de Jean Guiraud (Moebius) (LEE, GIRAUD, 2014). Em 1998, o surfista ganha uma série de 13 episódios de desenhos animados de curta duração. (SILVER, 2013).

Outro momento marcante na história editorial do herói prateado é a minissérie Réquiem (2007) escrita por J. Michael Straczynski (criador de He-man e Babylon 5, entre outros) e desenhada por Esad Ribic, em que o Surfista se desintegra e desaparece para sempre. Também em 2007, o Surfista Prateado protagoniza o filme Fantastic Four: Rise of the Silver Surfer - baseado na Trilogia de Galactus. Está presente em vários videogames da Marvel como personagem jogável para todos os consoles.

A história do surfista prateado nos remete a Galactus, o devorador de mundos, um ser semelhante a um buraco negro que se alimenta impessoalmente da energia de universo. Norrin Radd, um nobre do planeta Zenn-La, se oferece para servi-lo como arauto, para que Galactus poupe seu planeta. A barganha funciona e Galactus poupa Zenn- La.; Norrin Radd é transformado no Surfista Prateado, um ser com poderes extraordinários, condenado a buscar planetas para satisfazer a fome de Galactus.

E assim o Surfista foi aliado do vilão destruidor, encontrando vários personagens que o acusam pela sua colaboração no passado.

Além disso, ele tem uma jornada invertida: ele veio de uma realidade extraordinária e está preso em nosso cotidiano, desejando ardentemente voltar. Ele busca sempre fazer o que é certo, inclusive ajudando seus inimigos (o próprio Galactus), quando isso the parece justo. Ele não é movido pela vingança, buscando sempre soluçóes pacíficas para os conflitos. Em nenhum momento, o Surfista pensa em vencer seus adversários, mas sim em tornalos em aliados em função de seu objetivo: voltar ao planeta Zenn-La e aos braços de sua amada Shalla-Bal.

Assim foi sua vida até chegar à Terra, planeta em que ele conhece o Quarteto Fantástico, recupera a memória e, comovido pela nobreza dos humanos, impede que seu chefe se alimente. Como punição por sua traição, o devorador de mundos, nas primeiras versões, o aprisiona na terra. Nas versões mais recentes, Galactus amaldiçoa o surfista como um viajante perpétuo dos universos. Desde então, ele vaga sem destino pelo espaço sem esperança de um lar, de uma família ou de encontrar quem o aceite. (FANTASTIC FOUR, 1966)

Há duas diferenças fundamentais entre o antigo herói mitológico e o superherói contemporâneo: a dupla identidade e o tempo. Antigamente os heróis mitológicos existiram em um passado distante; hoje, os super-heróis vivem uma aventura aberta, com eventos que estão acontecendo e que vão ainda acontecer.

Em artigo sobre a dupla identidade dos super-heróis, Gomes (2017) argumentou que o super-herói tem duas características: a identidade secreta (o personagem-leitor) e ser uma repaginação ideológica de um mito, por meio de um determinado contrato de leiturá, de um determinado contexto sócio histórico de imaginação do personagem. No passado, o Super-Homem e o Capitão América eram heróis hegemônicos (se vestiam com a bandeira dos Estados
3. https://pt.wikipedia.org/wiki/ Surfista_Prateado. 
Unidos), enquanto o Batman e o Homem de Ferro eram milionários rebeldes, sem superpoderes mas com acesso a uma tecnologia avançada. As narrativas mais recentes (no cinema), alteram bastante esse esquema ideológico do pacto de leitura da Guerra Fria (VINGADORES, 2015; BATMAN, 2012).

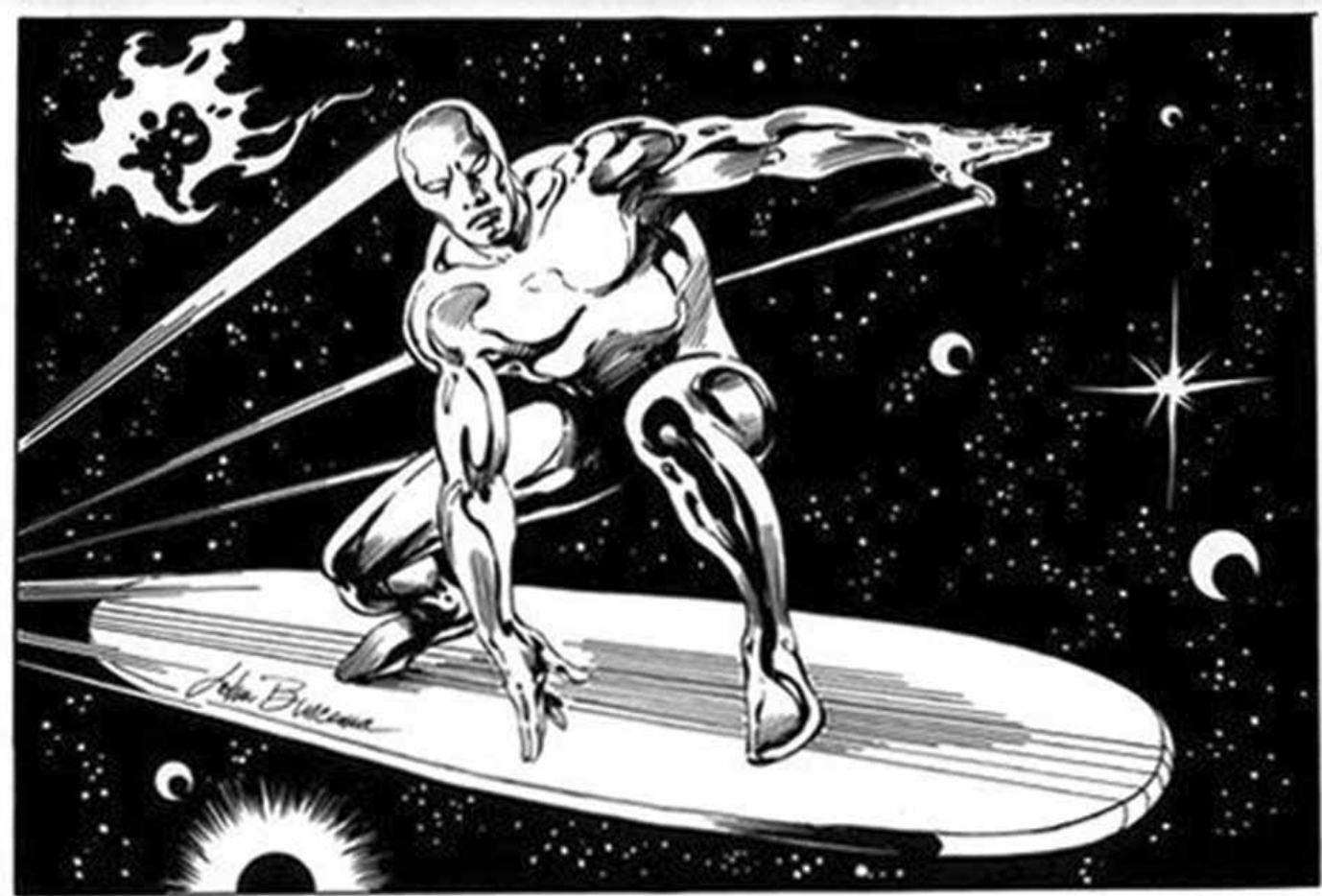

Figura 4 - 0 surfista de Kirby Fonte: https://www.pinterest.co.uk/pin/149392912612781587/

O Surfista Prateado não tem identidade secreta. Ele perdeu sua 'humanidade' (deixou de ser Norrin Radd) e deseja voltar a tê-la. E, do ponto de vista ideológico, o Surfista tenta ser neutro em relação aos conflitos, mas acaba se envolvendo com eles. No planeta do Dr. Moreau, em episódio da série animada, ele toma o partido de uma raça escravizada por outra, é escravizado também, consegue libertarse e tenta, sem sucesso, libertar o planeta oprimido. (SILVER SURFER, 1998)

Em outras situações, as tentativas de ajuda do Surfista acabam gerando problemas maiores ou são mal interpretadas. Ele acaba sempre se sacrificando por pessoas que não o reconhecem. Ele parece meio autista, tem falta de habilidades sociais e de comunicação.

Pode-se associar o símbolo do Surfista ao arquétipo do louco, o número zero do Tarô, que representa o eterno passageiro, o 'moto-perpétuo', a consciência do universo sempre impermanente (GOMES, 1998). O surfista está sempre em trânsito, sempre procurando voltar para o lugar do qual saiu. E o único 'Destino possível é a tentativa sem esperança de retorno a sua 'Origem'. Ele é privado de seu passado e de seu futuro, é um prisioneiro do eterno presente.

Além dessa 'espiritualidade laica' embutida no panteão cósmico do universo e de sua 'neutralidade política' (impossível em relação às injustiças sociais dos planetas que visita), o Surfista Prateado como personagem tem ainda características pessoais e estilísticas bem específicas: a honra, o gosto pelo equilíbrio, o respeito à natureza, a solidão do viajante. E, principalmente: o visual todo branco prata da energia cósmica das estrelas. A prata, segundo Andraus, se referindo especificamente ao Surfista Prateado, é "símbolo de pureza e de purificação da alma” (ANDRAUS, 2008, p.4).

Ele não come nem se alimenta. É 
incapaz de mentir. Não tem necessidades nem desejos. Sua prancha é feita da mesma energia cósmica de seu corpo e se comunica telepaticamente com o surfista.

As narrativas contemporâneas $\mathrm{da}$ mídia são uma nova forma de mitologia, voltada para o futuro (e não apenas para o passado - como a mitologia clássica). Estudar essas narrativas midiáticas é investigar a organização dos símbolos no imaginário coletivo atual. Há universos narrativos mais centrados na dicotomia entre o bem e o mal, como as histórias dos contos de fada, muitas vezes afirmando crenças do simbolismo dominante - tanto em relação à política como à religião. As narrativas de super-heróis e de ficção científica, por outro lado, são socialmente críticas, laicas e até antirreligiosas: os deuses são alienígenas e a magia foi substituída pela tecnologia. O personagem Galactus, por exemplo, que personifica a destruição e escraviza o Surfista como um batedor dos mundos que deseja devorar, não é eticamente 'mau'. Ele age assim porque é sua natureza ser o devorador de mundos. Ele foi o único sobrevivente da última contração do universo e luta para sobreviver até o fim da expansão cósmica iniciada pelo Big-Bang. Galactus é das entidades cósmicas dentro do universo Marvel que se comportam como deuses. Há também Uatu ou o Observador. Ele faz parte da raça alienígena dos Vigilantes. Eles se dedicam a observar os acontecimentos do Universo e são terminantemente proibidos de interferir no curso da história. Uatu é o vigia responsável pela Terra e já interferiu mais de uma vez para salvá-la, o que o levou a ser julgado (revista Captain Marvel n. 39) e marginalizado por outros vigias. ${ }^{45}$

Existem ainda Thanos (vilão recorrente no universo Marvel); Adam Warlock (que vive preso em uma anomalia em que o tempo se repete sempre); os irmãos gêmeos Infinito e Eternidade (dualidade masculino-feminina formada através das projeções da consciência de todos os seres vivos); entre outros personagens. ${ }^{6} 7$

Assim, o surfista interage com outros super-heróis Marvel, com humanos e com seres de outros planetas em seu círculo de existência transitória, mas sua origem está nessa dimensão ampliada do universo, em uma coexistência cósmica com seres com vidas de longa duração - principalmente nas narrativas da série de desenhos animados.

\section{4. https://pt.wikipedia.org/wiki/} Vigia_(Marvel_Comics).

\section{5. http://marvel.wikia.com/wiki/} Captain_Marvel_Vol_1_39.

\section{6. https://pt.wikipedia.org/wiki/} Adam_Warlock.

\section{7. https://pt.wikipedia.org/wiki/} Thanos.

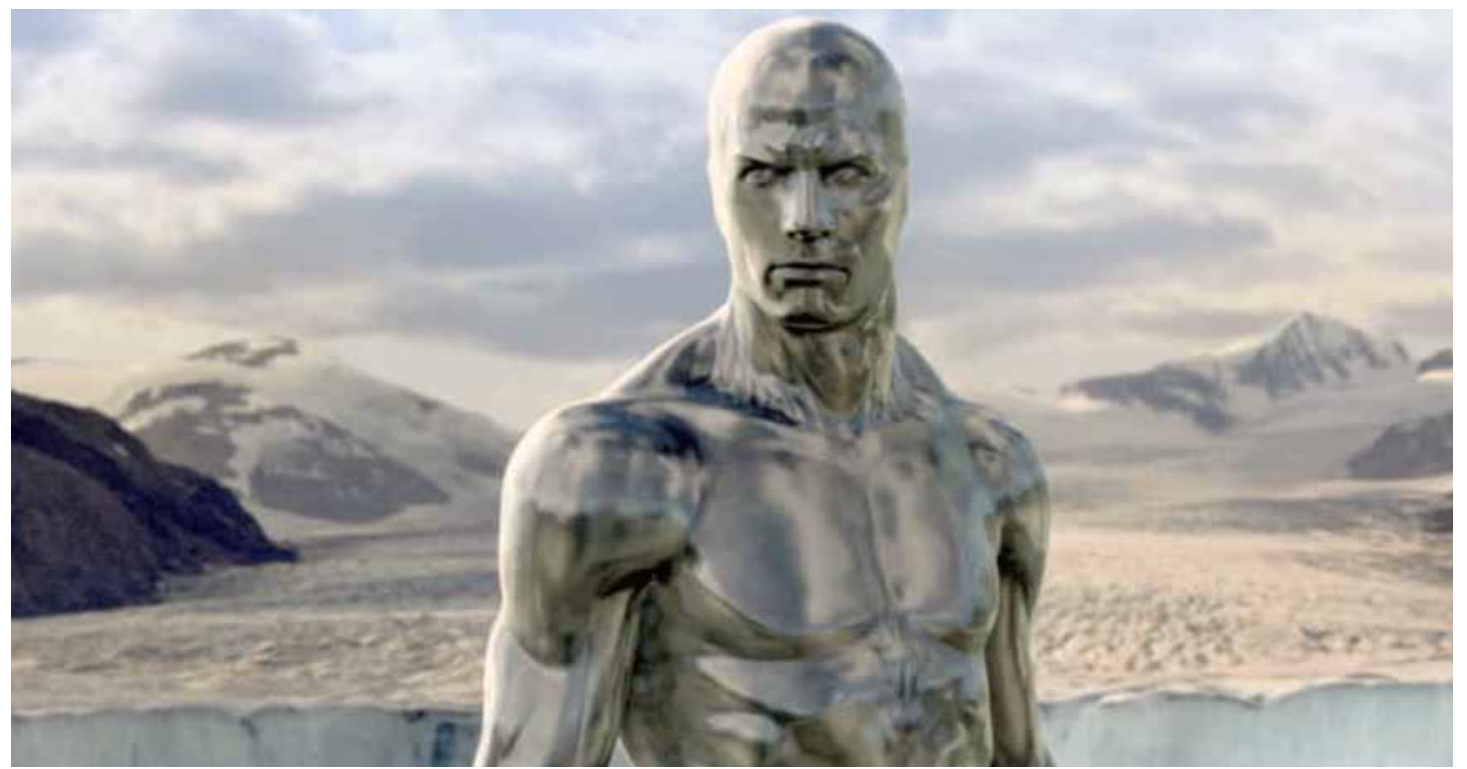

Figura 5 - Surfista no cinema

Fonte: https://www.maxim.com/entertainment/silver-surfer-marvel-movie-2018-2 
Gazy Andraus (2008) estuda o Surfista Prateado como símbolo do self, como um herói crístico - ao lado de Thor e do Super-Homem. Os três foram banidos de seus lugares de origem para viver na terra uma existência heroica. No caso do Surfista em particular, Andraus enfatiza ainda sua relação simbólica com o Quarteto Fantástico, em que o herói funciona como um quinto elemento (o Coisa seria a terra; Sr. Fantástico (o homem-elástico) representaria a água; Moça-Invisível, o ar; e Tocha-Humana, o fogo).

A tese principal de Andraus - de que o Surfista Prateado é um protagonista cuja narrativa descreve um processo do tipo espiritual - certamente é verdadeira. Porém, é preciso admitir que o personagem não se encaixa bem na Jornada do Herói de Campbell (ele não sai do cotidiano para a realidade extraordinária; ao contrário: sai de um universo cósmico para o mundo ordinário), nem no conceito transgressor $\mathrm{e}$ violento de herói de Lévi-Strauss. O surfista não tem o desejo de vingança ou de reparação das injustiças que sofreu.
O Surfista Prateado não é apenas um símbolo de transcendência espiritual, mas também está associado ao arquétipo do eterno estrangeiro, ao destino trágico de vagar permanentemente através de universos passageiros. Como função narrativa, seu personagem é um protagonista que tenta compreender e modificar sua relação com o antagonista, tornando-o um aliado. Seu único desejo e motivação é o retorno ao seu planeta natal - escondido por Galactus após sua libertação/traição.

Geralmente, a história do surfista se divide entre antes, durante e depois de ficar preso na Terra. Antes de encontrar o Quarteto Fantástico, o Surfista era apenas um sub vilão. $\mathrm{Na}$ Terra, converteu-se em um super-herói. E depois tornou-se um viajante das estrelas, dando um conteúdo poético a seu destino trágico. Enquanto o Surfista Prateado é um personagem simbolicamente semelhante a um anjo decaído, que deseja voltar à sua origem, alguns super-heróis aproximam-se da mitologia dos demônios e de suas narrativas de auto superação, como são os casos do Batman e do Demolidor.

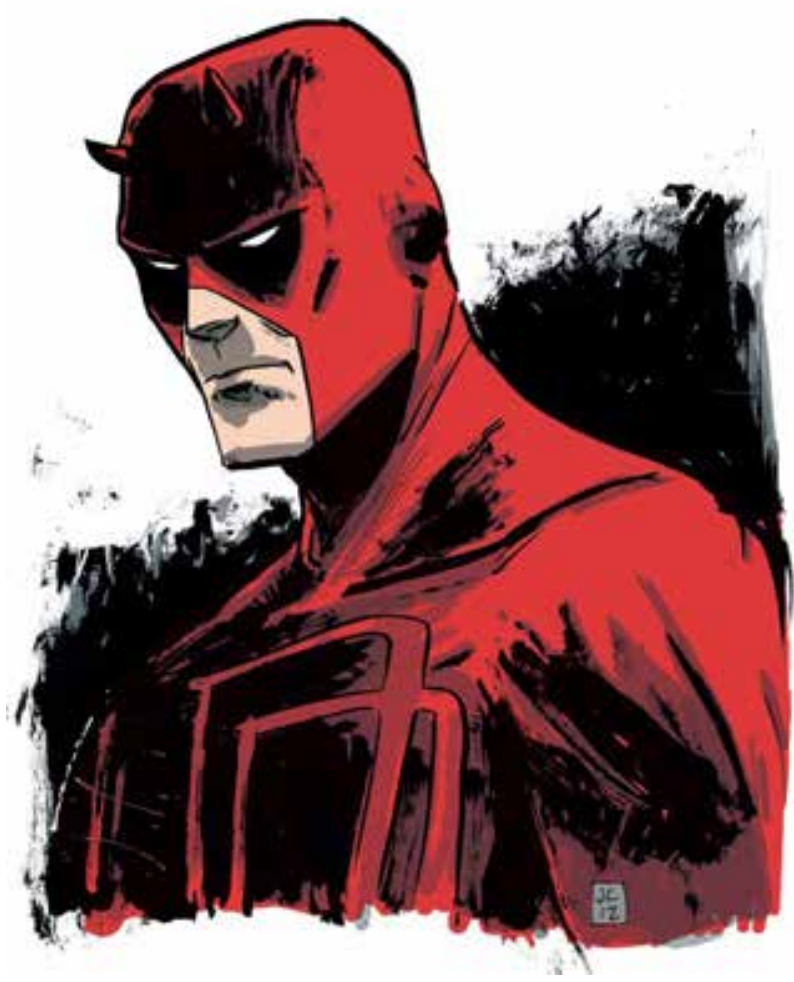

Figura 6 - Demolidor Fonte: http://www.manwithoutfear.com/daredevil.shtml 


\section{3-O homem sem medo}

O jovem Matthew Murdock fica cego quando salva um idoso de ser atropelado por um caminhão devido a sua carga radioativa. Além de tirar a visão de 'Matt', a exposição à matéria radioativa teve com efeito colateral o desenvolvimento dos seus outros sentidos para bem além da capacidade humana, como o sentido sonar (bi localização e reconhecimento através de batimentos cardíacos), que atua como a sua visão. Depois do acidente, Murdock é treinado secretamente por um sensei que também é deficiente visual: Stick, líder do clã ninja The Chaste. Stick - que também é mentor de Electra, sua futura parceira - the ensina artes marciais e a forma de controlar os seus novos sentidos ampliados. $\mathrm{O}$ pai de Matt, Jack Murdock, um pugilista fracassado de nome Daredevil, é morto pela máfia depois de se recusar a perder uma luta. Matt procura vingança contra os assassinos do seu pai e adota seu nome de lutas como superherói. Paralelamente, Matt também se tornar advogado e abre um escritório no bairro com seu melhor amigo, Franklin "Foggy" Nelson. (OLIVEIRA, 2012).

Demolidor foi criado em 1964 por Stan Lee e pelo artista Bill Everett. É um herói cego de um bairro de periferia de Nova Iorque, Hell's Kitchen. Mas foi na década de oitenta, com Frank Miller que o personagem se tornou relevante. Miller assumiu o posto de desenhista regular no n. 158. Passou a também assinar o roteiro a partir do n. 168, quando introduz a personagem Elektra. Com histórias de estilo cinematográfico, ambientadas no submundo (com prostitutas, assassinos de aluguel, mafiosos, psicopatas, mendigos etc.) de Nova York, Miller transformou o no primeiro personagem dos quadrinhos de grande tiragem voltado para um público mais adulto. (OLIVEIRA, 2012)

FrankMiller mergulhou o Demolidor num universo realista e assustador. Mais tarde, ele viria a repetir essa mesma fórmula na DC Comics, nas séries Batman: Ano Um e Batman: Cavaleiro das Trevas. Assim, embora o Batman tenha inspirado a criação do Demolidor, foi o novo padrão estético e narrativo do 'homem sem medo' que 'abriu as portas' para a atualização do 'homem-morcego'. A obra prima de Miller com o Demolidor é a série "Born Again" ("A queda de Murdock" no Brasil, publicada dos números 227 a 233, de 1986) (MILLER, MAZZUCHELLI, 2013). Nela, o protagonista tem sua identidade entregue ao rei do crime Wilson Fisk por Karen Page, uma ex-namorada, que trabalha de secretária no escritório da Murdock \& Nelson e termina como atriz pornô viciada em heroína. O Demolidor é um vigilante de bairro (de um bairro específico de uma cidade real), um 'herói-local' que enfrenta um universo de gângsteres, traficantes, policiais e políticos corruptos. Também é relevante destacar o lado religioso de Matt Murdock, que é católico e se confessa com padre regularmente na igreja:

Pelo menos no enredo bem conhecido de Miller e Smith, Matt vem de um lar religioso e tornase um adulto imbuído de uma distinta sensibilidade religiosa [...] Demolidor ressente-se do mal do mundo, do mesmo modo que uma pessoa devota e espiritualizada ficaria - vendo o mal não apenas como um fato inevitável e desagradável da vida, mas sim como um desvio de como as coisas deveriam ser. Ele sofre quando os inocentes sofrem e sente grande satisfação - pelo menos com uma sensação temporária de justiça e conclusão - quando a justiça é feita. (MORRIS, 2005, p.58)

O Demolidor é um justiceiro redentor. Ele se encaixa no conceito de herói- transgressor de Lévi-Strauss, mas não no da jornada do herói de Campbell. Ele vive em um cotidiano imanente, sujo e violento, sem transcendências. Ele parece um demônio, com chifres, vermelho e preto. Seu nome inglês é Daredevil, que significa 'danado', no sentido de intrépido' édiabólico' 
(embora em Portugal seja traduzido como 'Temerário'). Ele está associado, pela psicologia analítica de C. G. Jung, ao arquétipo da sombra, uma área da psique em que se escondem os sentimentos violentos. (JUNG, 2011; VON FRANZ,2002)

O Demolidor e a auto superação (OLIVEIRA, 2012, p. 55) é uma interessante descrição subjetiva do processo de resiliência (adaptação criativa que reinterpreta as limitações com vantagens diferenciais) do protagonista, que é deficiente visual e, em compensação, desenvolve um desempenho incomum de outros sentidos. Para ler A queda de Murdock, Oliveira aplica o modelo das cinco fases do luto sobre a morte (elaborado por Elisabeth Kubler-Ross) que caracterizam o comportamento psicológico diante de perdas em geral: raiva, negação, negociação, tristeza e aceitação.
Mas, além da tristeza, as situações dolorosas podem fazer com que descubramos em nós mesmos forças antes desconhecidas, faz com que repensemos nossas vidas e nossos valores, passando a perceber o que realmente é importante e o que é supérfluo, e podem nos transformar em pessoas mais ricas espiritual e emocionalmente. [...] A figura do Demolidor é um ícone emblemático dessa luta em superar tais problemas.

A resiliência ou a auto superação é o superpoder do Demolidor. Como lutador, ele se adapta ao seu oponente, descobre seus pontos fracos para derrota-lo.Seu desejo e sua motivação básica é a justiça feita à margem da lei. De dia, Murdock é um advogado, que age segundo a lei; à noite, o Demolidor é um justiceiro, que resolve seus casos fazendo justiça com as próprias mãos.

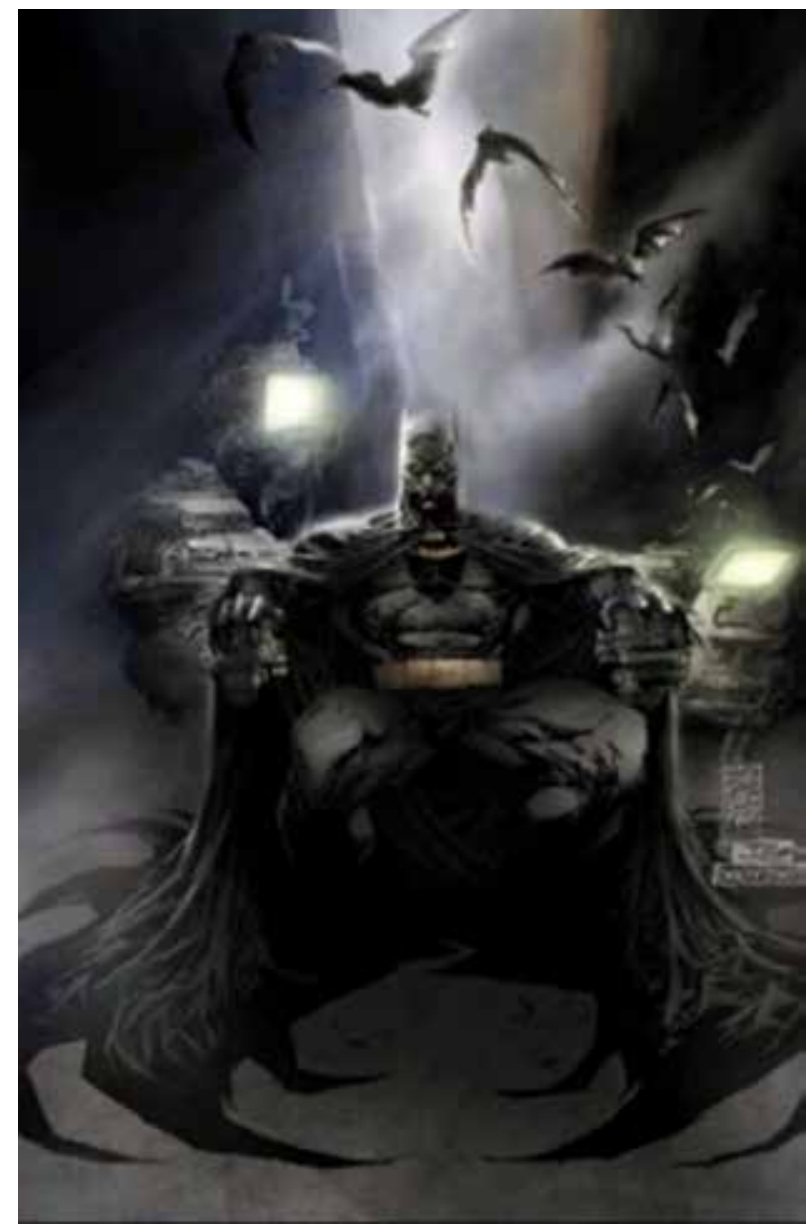

Figura 7 - Batman Fonte: https://crackberry.com/wallpaper/batman-bat-cave 


\section{4 - Luz nas trevas}

O caso do Batman é um pouco mais singular e complexo. Assim como Demolidor, Batman é uma representação do mal, representando tanto a sombra psíquica quanto a domesticação do desejo de vingança pela justiça (mesmo que fora da lei) em um mundo urbano e caótico extremamente cruel e violento. Assim como Demolidor, Batman conta a história de uma superação. Vítima de uma tragédia pessoal (o assassinato de seus pais), Bruce Wayne canaliza sua raiva e sua dor, dando um propósito a sua vida.

O foco da anatomia subjetiva desses personagens sombrios é o controle dos instintos, da violência e da vingança através da disciplina obsessiva. A capacidade de autocontrole é semelhante a um superpoder. Ambos personagens também trabalham com a inversão do medo: não temer a nada para torna-se temido por aqueles que vivem do crime.

Porém, em relação à dupla identidade, há uma evolução do homem-morcego em relação ao Demolidor. Embora o conflito de identidades faça parta do personagem, é possível dizer que os primeiros Batmen eram mais semelhantes ao Demolidor. Houve uma mudança de 'um superherói sem superpoderes' para um ser humano socialmente desajustado que sai de noite para caçar bandidos igualmente desajustados.

Apesar de ter superado sua fobia por morcego e o ter tornado um símbolo de terror para os criminosos, Batman continua com um sério problema de confiança. (BATMAN BEGINS, 2005). Não confia em ninguém e é justamente isso que o torna uma pessoa tão confiável, apesar de extremamente solitário.

As questões são: Vou estar seguro de novo? Será que poderei confiar em alguém... e que elas não serão mortas? E Bruce Wayne é a pessoa que sempre irá perguntar: estarei seguro de novo? Então é melhor fazer segurança com as próprias mãos! [...] (BATMAN, 2008, $06: 31)$

E também é preciso ressaltar: ao mesmo tempo em que os Batmen mais recentes são mais humanos $e$ desequilibrados, o aspecto mítico do morcego foi democratizado com outras pessoas usando seu capuz e outros personagens adotando sua marca. 'Batman' torna-se uma 'franquia narrativa' de luta contra o crime.

Com o passar das décadas, com a amizade com o Super-Homem (um herói do tipo oposto) e com a participação como estrategista da Liga da Justiça, o HomemMorcego se desterritorializa de Gotham City e da Batcaverna, visitando outros locais e universos. Torna-se um herói global e passa a ter um papel de destaque nas reorganizações dos multiversos narrativos da DC Comics ${ }^{8}$.

Para explicar essa metamorfose, a dissertação de mestrado Batman: uma luz sobre o Cavaleiro das Trevas - mediações, midiatizações, transmidiatizações (TAVARES, 2007) descreve e analisa o personagem ao longo de sua história, através da método hermenêutico e das noções de mediação, midiatização e transmidiatização. $\mathrm{O}$ trabalho demonstra como o personagem é uma mediação entre a indústria cultural e diferentes públicos. Mediação, com 'é, é um agenciamento que transforma conflitos em diálogos;

Já 'midiatização' (com ì) significa um regime em que as relações entre diferentes agentes são mediadas (com 'é) pelos meios de comunicação. Dizse que algo foi 'midiatizado' quando sua existência virtual se torna mais importante do que sua materialidade. Já o termo 'transmidiatização' evoca a ideia de múltiplos suportes e de descentralização através de redes, de um produto simbólico plural e complexo, comercializado como franquia. É a midiatização desenvolvida de forma segmentada e interativa. (TAVARES, 2017,30)
8. O conflito entre muitos anos de serialização e a necessidade de coerência interna do mundo narrado, levou a criação do conceito de 'Multiverso', um conjunto de muitos universos, ou de uma realidade paralela e relativa no interior do universo narrativo. Como por exemplo, na história em quadrinhos de 1964 "Crise na Terra-3" (escrita por Gardner Fox para Justice League of America \#29-30) e na graphic novel de 2000 JLA: Earth 2 (de Grant Morrison). Essas narrativas, apesar de serem da Liga da Justiça e não do Batman, são bastante importantesnãoapenas devidoao papel central dohomem-morcego na narrativa, mas sobretudo porque explicam e desencadeiam toda uma mudança no universo narrativo da DC Comics.'Os Novos 52 ' são a nova repaginação do universo DC, a matriz atual para construção do mundo de seus super-heróis através de narrativas seriadas. Os Novos 52 (cinquentae dois) é uma minissérie de histórias em quadrinhos publicadas originalmente, semanalmente, durante 52 semanas. 52 mostra aos leitores o que aconteceu no Universo DC durante o período referente ao salto cronológico de umano ocorridoem todas as séries mensais da editora. http://pt-br. dc.wikia.com/wiki/Os_Novos_52. 
9. 'Pulp fiction' é nome dado, de forma pejorativa, às revistas feitas com papel de baixa qualidade que traziam histórias eróticas, de terror e ficção científica. Os Pulps precederam os comics de super-heróis.
O personagem 'Batman' é uma mediação entre um público leitor e a indústria cultural, uma negociação entre o interesse das pessoas e da sociedade. Batman é um 'bem público' cultural. E sua mediação exige um 'pacto de leitura' entre os produtores e a audiência, que passa por várias fases e mudanças no decorrer das oito décadas de vida do personagem (MORRISON, 2012):

+ Era de Ouro (1938-1956) A segunda grande guerra mundial marcou o surgimento dos super-heróis. Umberto Eco (1991, 2015) e Grant Morrison (2012) enfatizam o grande sentimento de impotência e frustração dos trabalhadores em relação à guerra como sendo um fator do sucesso dos super-heróis, que funcionavam como compensação e como uma válvula de escape. Batman, nesse contexto, com sua imagem sinistra e misteriosa, "emulava as figuras do Drácula, do Fantasma da Ópera e os vigilantes mascarados dos pulps ${ }^{9}$ do fim dos anos 1930" (TAVARES, 2017, 39). Nessa época, o Homem-Morcego carregava armas de fogo em seu cinto de utilidade e matava os criminosos ao invés de prendê-los. Batman não era exatamente um herói (era um bandido que lutava com outros bandidos para se redimir) e não se encaixava na jornada de Campbell.

+ Era de Prata (1956-1970) A Guerra Fria entre Estados Unidos e União Soviética teve várias consequências para o universo narrativo dos quadrinhos, dentre as quais o Macarthismo (que em tudo via a ameaça comunista) e pleiteava o patrulhamento moral da sociedade. O psicólogo Fredric Wertham escreveu um relatório alertando sobre a suposta relação entre os quadrinhos e a delinquência juvenil (inclusive insinuando uma relação homossexual entre Batman e Robin). As editoras, sob pressão do Senado americano, criaram o Comic Code Authority proibindo quadrinhos contendo "sangue, insinuações sexuais, violência excessiva", considerados inadequados para o público infantojuvenil (NYBERG, 1998). Os vigilantes mascarados tornou-se ultrapassados. Muitas publicações saíram de circulação, mas o Batman sobreviveu. Batman se torna um herói de ficção científica para as crianças, antecipando equipamentos tecnológicos muito antes deles existirem (o bat-móvel tem GPS conectado ao batsatélite, o bat-computador acessa arquivos e bancos de dados remotos através da linha telefônica, entre outros). Começa a parceria com o Superman e com a Liga da Justiça.

+ Era de Bronze (1970-1984) O filmes seriados (1949, 1953) e principalmente a série de TV (1966) desencadeiam o processo de midiatização do personagem. Batman se torna um ícone pop $\mathrm{da}$ contracultura. Enquanto, nos quadrinhos, Denny O'Neil reposiciona o Batman como investigador e detetive; nas mídias audiovisuais, o homem-morcego protagoniza várias series em animação ao lado dos demais super-heróis da DC Comics focadas no público infantil com temáticas mais leves e lúdicas que a trilha mais séria, madura dos quadrinhos (TAVARES, 2017).

+ Era das Trevas (1984-1998) A publicação da Batman the Dark Knight Returns, em 1986, escrita e desenhada por Frank Miller, marca o retorno de Batman a suas origens violentas. $\mathrm{O}$ trabalho de Miller tornou-se um padrão para as décadas seguintes e radicalizou uma tendência contra a infantilização do personagem, derivadas das adaptações audiovisuais. Os filmes de Tim Burton (1989; 1992) e Joel Schumacher (1997; 2005) mantiveram essa defasagem estética narrativa, se aproximando mais do Batman das eras passadas do que no estilo ultrarrealista de Miller (ANAZ, 2016). Burton faz um Batman gótico, sombrio, mas com inimigos extravagantes e coloridos, como na Era de Ouro; Schumacher, produz um Batman semelhante aos das Eras de Prata e Bronze. 
O contraste entre o Batman audiovisual e o Batman gráfico diminuiu em 1993, com Batman: Mask of the Phantasm o longametragem de animação produzido para TV por Paul Dini e Bruce Timm. Porém foi apenas com a trilogia cinematográfica (2005; 2008; 2012) da dupla Christopher Nolan (diretor) e Christian Bale (ator) que o Cavaleiro das Trevas sai do papel e ganha os contornos hiper-realistas da estética de Miller. Também agora o personagem se adapta à Jornada do Herói - como demonstra Tavares (2017, p. 135). Também na Era das Trevas aprofundase $o$ processo de transmidiatização do personagem. Além de presente em múltiplas plataformas (histórias em quadrinhos, filmes, desenhos animados, séries de televisão, brinquedos); a participação dos fãs a criação narrativa do personagem se tornou evidente. O próprio conceito visual do Batman de Nolan deriva de um fã-filme: Batman Dead End (2003), do diretor Sandy Collora ${ }^{10}$.

+ Era Moderna (1998-2013) A Queda do Morcego' de 1993 é a história em quadrinhos que marca a transição da Era das Trevas para a Era Moderna, remodelando o Batman de Miller, retirando Bruce Wayne como o homem por detrás da máscara e introduzindo um visual de armadura meio robótico (DIXON et al, 2008). No cinema, esse conceito do personagem está presente em Batman vs Superman (2016), de Zack Snyder. Porém, o que realmente caracteriza a Era Moderna para o Batman é a extensão e capilaridade de sua condição de franquia. Batman é o personagem que tem mais videogames e séries de TV. Existem, pelo menos, 30 filmes de animação longa-metragem protagonizada pelo personagem (TAVARES, 2017). Há um Batman para cada público (infantil, infantil feminino, juvenil, nostalgia, adulto, nerd). A diversidade de adaptações e versões produzidos por fãs nas diversas plataformas de mídia é incalculável e novos produtos midiáticos surgem todos os dias.

Batman tornou-se um superherói através de sua midiatização, dele ter saído da condição de um heróitransgressor, violento e inovador (ante tradicional) de Lévi-Strauss passando a ser um herói espiritual dentro da jornada de autoconhecimento e ressurreição de Campbell6. E o trabalho de Tavares - por meio das categorias descritivas de mediação, midiatização e transmidiatização -, narra as diferentes etapas dessa transformação de demônio em busca de redenção ao herói que conquista a vitória através da perfeição.

Assim como Batman se aproxima do Demolidor, o Surfista Prateado é semelhante ao Super-Homem ${ }^{11}$.

\section{Conclusão}

É claro que os anjos e os demônios, no fundo, somos nós. O Batman, o Demolidor e os heróis vigilantes são representações equivalentes ao lado mais instintivo e voltado para o controle do território; enquanto o Super-Homem, o Surfista Prateado, Thor são representações do lado mais universal e transcendente de nossa humanidade, representada no passado pelos deuses solares e heróis míticos.

Tanto o Surfista Prateado como Demolidor encaixam-se apenas parcialmente no modelo de morte e renascimento de Campbell, eles não fazem uma jornada de tarefas heroicas, nem aspiram à imortalidade. O Surfista $\mathrm{faz}$ uma parte incompleta da jornada ao inverso, ele foi do extraordinário ao ordinário e deseja retornar ao lar e não consegue.

O Demolidor, por outro lado, não se encaixa no modelo narrativo do violento herói-transgressor de Lévi-Strauss, embora a transgressão tenha sido substituída pela deficiência visual e a vingança destruidora do retorno à tribo também tenha sido trocada pela justiça feita às margens da lei.
10. https://www.youtube.com/ watch?v=bhEcP86cGt8

11. A ideia de um super-homem mítico, representando o self, no lugar antes ocupado pelos deuses solares, pela união arcaica entre Apolo (a forma) e Dionísio (a transmutação) substituída pelo símbolo do Cristo (a renúncia); surge com o filósofo alemão Friedrich Nietzsche. No livro Assim Falou Zaratustra, ele descreve como se tornar um 'Além- Homem' (Übermensch) através vontade de potência manifesta criativamente em superar o niilismo, em reavaliar valores velhos e criar novos em um processo contínuo de superação (GOMES, TAVARES, 2012). Hitler utilizou o conceito de Nietzsche para criar um ideal utópico para raça ariana, mas foram dois garotos judeus americanos (Jerry Siegel e Joe Shuster), fãs de ficção científica e dos fanzines 'pulp' que deram vida a um dos maiores mitos do século XX. Gomes \& Tavares sugerem a reconfiguração do mito do messias através de um personagem salvador alienígena e seu enquadramento na jornada do herói. A história do Super-Homem também foi sendo expandida e alterada gradativamente ao longo dos anos para acompanhar a evolução do público. No sentido contrário da mitificação do Batman e de sua transformação em um herói e sem as oscilações da Mulher Maravilha entre o mitológico e o cotidiano; oSuperHomem foi se tornando cada vez mais humano eemocionalmente vulnerável. 


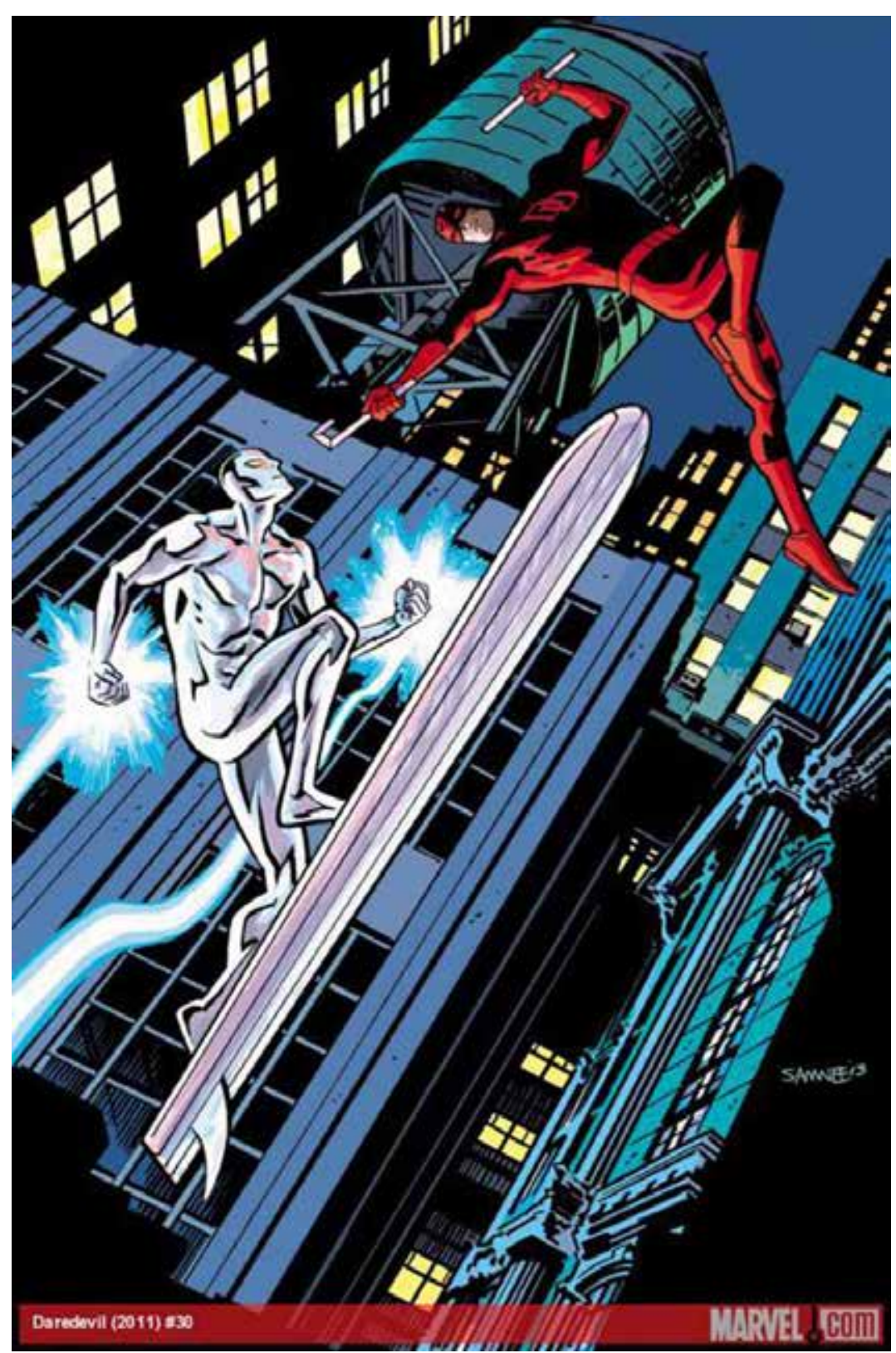

Figura 8 - O Surfista e o Demolidor Fonte: Revista Daredevil, n. 30, August 2013. https://themacguffinnet.wordpress.com/2013/08/22/daredevil-30-review/

Ambos merecem ser chamados de heróis porque, segundo a definição adotada são protagonistas que 'fazem coisas erradas pelos motivos certos', que se sacrificam pela transgressão de regras - mas de modos diametralmente diferentes.

Se comparamos o tipo de herói do Surfista Prateado (que 'caiu' de um universo transcendente, como Thor, Mulher Maravilha ou Super-Homem) com tipo de herói do Demolidor (que vive, sem esperanças, preso no mundo imanente, como o Homem-Aranha ou o Batman), a diferença fundamental a se revelar é a questão da identidade secreta. Enquanto no caso do Demolidor (e dos heróis vigilantes em geral), a identidade secreta é a identidade verdadeira; no caso dos heróis de outros mundos ou dimensões, a identidade cotidiana é que é falsa ou simplesmente não existe. O Batman é um milionário Bruce Wayne que se veste de morcego à noite; enquanto o Super-Homem é o alienígena Kal-El, que se disfarça de Clark Kent para conviver conosco. 


\begin{tabular}{|l|c|l|}
\hline \multicolumn{1}{|c|}{ XAMANISMO HAVAIANO } & FREUD & \multicolumn{1}{c|}{ PATCHWORK } \\
\hline Unihipili (criança/subconsciente) & ID & Eu Inferior (corpo instintivo ou criança ferida) \\
\hline Uhane (mãe/ consciente) & EGO & Ego, Máscara ou Autoimagem idealizada \\
\hline Aumakua (pai/superconsciente). & SUPERGO & Eu Superior (Centelha Divina) \\
\hline
\end{tabular}

TABELA 1: Estrutura ternária de psique

Fonte: O próprio autor.

O xamanismo havaiano costuma dividir o homem em três entidades com relativa autonomia: o filho, a mãe e o pai. $\mathrm{O}$ eu-filho seria o agir involuntário, instintivo, um corpo de desejos, muitas vezes frustrados e inibidos. $\mathrm{O}$ eu-mãe é a ação consciente, um corpo de atenção e cuidado, uma mediação entre animalidade e espiritualidade, uma identidade que criamos para educar e esconder o eu-filho. E, finalmente, o eu-pai corresponde à identidade simbólica ancestral (ao animais de poder', ao orixá de cabeça, aos signos astrológicos, entre outras possibilidades).

Essa forma de entender o ego ${ }^{12}$ é semelhante à toponímia freudiana da psique, que estabelece o 'Id', núcleo de emergem as pulsóes de vida e de morte; o 'Ego', que faz a mediação entre o desejo e a culpa; e o 'Superego', que faz a supervisão e controle mental estabelecendo regras e limites. A diferença é que Freud entende o Superego como uma instancia castradora, resultando do complexo de Édipo e da socialização. A neurose seria produto de seus excessos; a psicose, de sua ausência funcional.

Por outro lado, tanto o xamanismo havaiano quanto outras linhas de trabalho psicológico e espiritualista - como a metodologia de autoconhecimento Patchwork (PIERRAKOS, 1993) entendem a noção de Superego como sendo um 'eu superior' ou anjo da guarda.

Ocultando o Eu Inferior existe uma máscara, uma autoimagem idealizada, uma representação glorificada de quem achamos que deveríamos ser e que tentamos fingir que somos" (...) "são essas duas camadas da personalidade que escondem o Eu Superior. (1993, p. 20).

Este modelo ternário descende da crença de que temos um demônio pessoal e um anjo da guarda; e sua grande vantagem consiste em colocar o ego como observador tanto em relação aos impulsos instintivos como às demandas espirituais. Gomes (2017) defendeu que o Ego, ou personagem-leitor, correspondia a identidade secreta dos super-heróis. A hipótese agora é que, há super-heróis que representam a relação Ego-Id (como o Demolidor) e outros super-heróis que correspondem a relação Ego-Self (como o Surfista Prateado).

\section{Referências}

ANAZ, Sílvio Antonio Luiz. O sucesso do arquétipo do herói vigilante: ciência, tecnologia e ética na trilogia cinematográfica O Cavaleiro das Trevas. Comunicação, Mídia e Consumo, São Paulo, v. 13, n. 36, p. 94-111, jan./abr. 2016. Disponível em: http://revistacmc.espm.br/index.php/ revistacmc/article/view/1073/pdf Acesso em: 25 jul. 2018.

ANDRAUS, Gazy. A questão espiritual nas histórias em quadrinhos de Thor, Surfista Prateado e Super-Homem. CONGRESSO BRASILEIRO DE CIÊNCIAS DA COMUNICAÇÃO, 31으. - Natal, RN, 2008. Disponível em: http://www.intercom.org.br/papers/ nacionais/2008/resumos/R3-0784-1. html. Acesso em: 25 jul. 2018.
12. O Ego é a identificação/ negação da consciência com as formas estruturais da psique. Mas, há duas formas distintas de o compreender: a oriental (que o polariza com a consciência) e a ocidental (ou ternária). A oriental deseja que ele seja transcendido pela consciência. Um belo exemplo atual dessa forma é a de Eckahart Tolle: "O ego é um conglomerado de formas de pensamento recorrentes e de padrões emocionais e mentais condicionados que estão investidos de uma percepção do Eu" (TOLLE, 2007, 52-53). Para Tolle, o Ego é a ilusão do tempo, uma sucessão de momentos - mas o passado só existe quando nos lembramos e o futuro só existe quando nós o imaginamos); a consciência é a presença, a sensação pessoal imediata. 
CAMPBELL, Joseph. O herói de mil faces. São Paulo: Editora Cultrix/Pensamento, 1995.

O poder do mito. São Paulo:

Editora Palas Athena, 1990.

DIXON, Chuck et al. A queda do morcego. São Paulo: Panini, 2008. 2v.

ECO, Umberto. OSuper-Homem de massa: retórica e ideologia no romance popular. São Paulo: Perspectiva, 1991. (Debates: 238).

Apocalipticos e integrados. São Paulo: Perspectiva, 2015.

FANTASTIC FOUR, New York, Marvel Comics, v. 1, ns. 48-50, Mar (Mar./May 1966 GOMES, Marcelo Bolshaw. O herói de duas faces: a dupla identidade dos superheróis. 9a Arte, São Paulo, Observatório de Histórias em Quadrinhos da Escola de Comunicações e Artes da Universidade de São Paulo, v. 6, n. 1/2,,, 2017. Disponível em: http://www2.eca.usp.br/nonaarte/ ojs/index.php/nonaarte/article/ view/198/230. Acesso em 25 jul. 2018.

O Tarô como linguagem simbólica: uma cartografia arquetípica. (Inédito). 1998. Disponível em: https:// drive.google.com/drive/u/0/folders/1_eb XlKE2YMb5L620rmsxEjBP4AYB_2ri. Acesso em 16 jul. 2018.

; TAVARES, Dickson.

Trinity: o triângulo arquetípico da DC. Imaginário! João Pessoa, n. 12, p. 4979, jun. 2017. Disponível em: http:// marcadefantasia.com/revistas/imaginario/ imaginario11-20/imaginario12/3-trinity. pdf. Acesso em: 31 jul. 2018.

Superman: o ícone e o mito. Imaginário! João Pessoa, n.2, p. 97107, jul. 2012. Disponível em: http:// marcadefantasia.com/revistas/imaginario/ imaginario $01-10 / \mathrm{imaginario} 02 /$ imaginario-2.pdf. Acesso em: 25 jul. 2018.

JUNG, C. G. Aion. Estudo sobre o simbolismo do si-mesmo. 8. ed. Petrópolis: Vozes, 2011.

LEE, Stan; GIRAUD, Jean. Surfista Prateado: Parábola. São Paulo: Panini, 2014. LEVI-STRAUSS, Claude. O cru e o cozido: Mitológicas I. São Paulo: Cosac Naify, 2004.
Do mel às cinzas: Mitológicas II. São Paulo: Cosac Naify, 2005.

. A origem dos modos à mesa: Mitológicas III. São Paulo: Cosac Naify, 2006.

O Homem nu: Mitológica IV. São Paulo: Cosac Naify, 2011.

MILLER, Frank; MAZZUCCHELLI, David. A queda de Murdoch. São Paulo: Panini; Salvat, 2013.

MORRIS, Tom. Deus, o diabo e Matt Murdock. In: IRWIN, William (Coord.). Super-heróis e a filosofia: Verdade, justiça e o caminho socrático. São Paulo: Madras, 2005. p. 55-69.

MORRISON, Grant. Superdeuses: mutantes, alienígenas, vigilantes, justiceiros mascarados e o significado de ser bumano na era dos superheróis. São Paulo: Seoman, 2012.

NYBERG, Amy Kiste. Seal of approval: the history of the comics code. Jackson. MS: University Press of Mississippi, 1998.

OLIVEIRA, Daniel. O Demolidor e a auto superação. Imaginário!, João Pessoa, Ed. Marca de Fantasia, n. 2, p. 55-81, jul. 2012. PIERRAKOS, Eva. Não temas o mal: o método Patchwork para transformação do Eu Inferior. Tradução Sérgio Luiz dos Reis Lasserre. São Paulo: Cultrix, 1993.

STRACZYNSKI, Michael J.; RIBIC, Esad. Surfista Prateado: Réquiem. São Paulo: Panini, 2008.

TAVARES, Dickson. Batman: uma luz sobre o Cavaleiro das Trevas - mediações, midiatizações, transmidiatizações. Rio de Janeiro, Universidade Federal do Rio Grande do Norte, 2017. Dissertação de mestrado. Programa de Pós-Graduação em Estudos de Mídia. Disponível em: https://repositorio. ufrn.br/jspui/handle/123456789/23599. Acesso em: 25 jul. 2018.

TOLLE, Eckhart. Um novo mundo: o despertar de uma nova consciência. Rio de Janeiro: Ed. Sextante, 2007.

VOGLER, Christopher. A jornada do escritor. Rio de Janeiro, Ampersand Editora, 1997.

VON FRANZ, M. L. A sombra e o mal nos contos de fada. 3 ed. Paulus. São Paulo: 2002. 


\section{Referências audiovisuais}

AVENGERS: Age of Ultron. Produção executiva: Victoria Alonso, Louis D’Esposito, Jon Favreau, Alan Fine, Jeremy Latcham, Stan Lee, Patricia Witche. Direção: Joss Whedon. New York: Marvel Studios; Burbank, CA: Walt Disney Studios, 2015. BATMAN. Direção: Tim Burton. Los Angeles: Warner Brothers, 1989. 126m.

THE BATMAN. Direção: Lambert Hillyer. Culver City, CA: Columbia Pictures, 1943. 15 episódios, $\mathrm{p} / \mathrm{b}$.

BATMAN: Mask of the Phantasm. Produção: Benjamin Melniker, Michael Uslan. Direção: Eric Radomski, Bruce W. Timm. Los Angeles: Warner Brothers, 1993. BATMAN: a serie de TV. [Filme-Video] Produção executiva: William Dozier. Los Angeles: Twenty Century Fox Television; Greenway Productions, 1966-1968.

BATMAN Begins. Direção: Christopher Nolan. Los Angeles: Warner Brothers, 2005.

BATMAN Forever. Direção: Joel Schumacher. Los Angeles: Warner Brothers, 1995.

BATMAN Returns. Direção: Tim Burton. Los Angeles: Warner Brothers, 1992.

BATMAN and Robin. Direção: Spencer Gordon Bennet. Culver City, CA: Columbia Pictures, 1949. 15 episódios, p/b.

BATMAN \& Robin. Direção: Joel Schumacher. Los Angeles: Warner Brothers, 1997.

BATMAN vs Superman: the origin of justice. Produção: Charles Roven; Deborah Snyder. Produção executiva: Christopher Nolan; Emma Thomas; Geoff Johns; Direção: Zack Snyder. Los Angeles: Warner Brothers;,DC Comics, 2016. 151m.

BATMAN unmasked. Produção de Rick Hull. Los Angeles: Prometheus Entertainment, 2008.

THE DARK Knight. Produção: Legendary Pictures, Syncopy Films, DC Comics. Direção: Christopher Nolan. Los Angeles: Warner Brothers, 2008.

THE DARK Knight Rises. Produção: DC Comics, Legendary Pictures, Syncopy Films.
Direção: Christopher Nolan. Los Angeles: Warner Brothers, 2012.

FANTASTIC Four: Rise of the Silver Surfer. Produção: Avi Arad, Bernd Eichinger, Ralph Winter. Direção: Tim Story. Roteiro: Don Payne, Mark Frost. New York: Marvel Studios; Constantin Film; 2007. 91 min.

SILVER Surfer: the animated series. Direção: Roy Allen Smith e Tony Pastor Jr. New York: Marvel Entertainment, 1998. 13 episódios. 